\title{
Differences Within Practices in Opioid-Prescribing Patterns of Orthopedic Surgeons and in Subsequent Rates of Chronic Opioid Use, 2012-2014
}

\author{
Dan P. Ly, M.D., M.P.P. \\ Interfaculty Initiative in Health Policy, Harvard University, Cambridge, MA, USA.
}

KEY WORDS: opioids; orthopedic surgery; chronic opioid use.

J Gen Intern Med 34(4):529-31

DOI: $10.1007 / \mathrm{s} 11606-018-4745-7$

() Society of General Internal Medicine 2019

\section{INTRODUCTION}

Chronic opioid use, to which physician opioid-prescribing behavior may contribute, is associated with overdose and death. ${ }^{1,2}$ Prior research has found that higher opioidprescribing intensity among physicians in the same emergency department is associated with greater chronic opioid use. ${ }^{3}$ Whether a similar relationship holds for surgeons within the same practice for common outpatient surgical procedures, such as arthroscopic meniscectomies, is unknown.

\section{METHODS}

I performed analyses using 2011-2014 claims data for a random 20\% sample of Medicare beneficiaries. I identified arthroscopic meniscectomies performed on beneficiaries aged 65 and over who were continuously enrolled in Medicare Parts $\mathrm{A}, \mathrm{B}$, and $\mathrm{D}$ for at least 6 months before the procedure and at least 12 months after who did not have a hospice claim or cancer diagnosis during this time interval. ${ }^{3}$ Consistent with prior literature on surgical patients, I excluded patients with 7 or more days of opioids supplied in the 6 months prior to the procedure. ${ }^{4}$

Using Part D data, I attributed the first oral opioid prescription filled by patients within 14 days of the procedure to the surgeon. I calculated the median dose in morphine equivalents by surgeon after meniscectomies.

Table 1 Patient Characteristics by Surgeon Dose Intensity, 2012 to 2014

\begin{tabular}{|c|c|c|c|c|}
\hline Characteristic & $\begin{array}{l}\text { All patients } \\
(N=2691)\end{array}$ & $\begin{array}{l}\text { Patients treated by low- } \\
\text { dose prescribing surgeons } \\
(N=1360)\end{array}$ & $\begin{array}{l}\text { Patients treated by high- } \\
\text { dose prescribing surgeons } \\
(N=1331)\end{array}$ & $\begin{array}{l}P \text { value for difference between } \\
\text { patients treated by high-dose versus } \\
\text { low-dose prescribing surgeons }\end{array}$ \\
\hline Age (year) & 71.8 & 72.0 & 71.7 & 0.09 \\
\hline Female $(\%)$ & 57.5 & 59.1 & 55.9 & 0.09 \\
\hline White, non-Hispanic (\%) & 92.1 & 92.4 & 91.9 & 0.65 \\
\hline $\begin{array}{l}\text { Medicare-Medicaid dual } \\
\text { eligible (\%) }\end{array}$ & 4.5 & 4.6 & 4.4 & 0.87 \\
\hline Currently disabled (\%) & 1.9 & 1.9 & 2.0 & 0.94 \\
\hline $\begin{array}{l}\text { Number of chronic } \\
\text { conditions (number) }\end{array}$ & 2.17 & 2.18 & 2.16 & 0.73 \\
\hline \multicolumn{5}{|c|}{ Conditions present in the prior year } \\
\hline $\begin{array}{l}\text { Acute myocardial } \\
\text { infarction }(\%)\end{array}$ & 1.6 & 2.1 & 1.2 & 0.08 \\
\hline Atrial fibrillation (\%) & 6.5 & 6.5 & 6.5 & 0.93 \\
\hline $\begin{array}{l}\text { Chronic kidney disease } \\
(\%)\end{array}$ & 8.2 & 8.6 & 7.9 & 0.50 \\
\hline $\begin{array}{l}\text { Congestive heart failure } \\
\text { (\%) }\end{array}$ & 8.2 & 9.0 & 7.4 & 0.13 \\
\hline Diabetes $(\%)$ & 22.4 & 22.9 & 21.8 & 0.47 \\
\hline Hyperlipidemia (\%) & 70.2 & 69.7 & 70.7 & 0.57 \\
\hline Hypertension (\%) & 65.0 & 64.9 & 65.1 & 0.94 \\
\hline Alzheimer's disease $(\%)$ & 0.3 & 0.2 & 0.4 & 0.46 \\
\hline $\begin{array}{l}\text { Cerebrovascular disease } \\
(\%)\end{array}$ & 5.5 & 6.0 & 4.9 & 0.19 \\
\hline $\begin{array}{l}\text { Chronic obstructive } \\
\text { pulmonary disease }(\%)\end{array}$ & 11.1 & 10.4 & 11.8 & 0.24 \\
\hline Depression (\%) & 17.8 & 17.4 & 18.2 & 0.61 \\
\hline $\begin{array}{l}\text { Average median dose } \\
\text { (morphine equivalents) }\end{array}$ & 186 & 70 & 304 & $<0.001$ \\
\hline $\begin{array}{l}\text { Rate of chronic opioid } \\
\text { use }(\%)\end{array}$ & 0.30 & 0.07 & 0.53 & 0.03 \\
\hline
\end{tabular}

Dose intensity refers to treatment by surgeons in the top quartile (high-dose) and bottom quartile (low-dose) within the same practice of median dose of first opioid prescription filled within 14 days of a meniscectomy [or highest and lowest median dose for practices with fewer than four surgeons]. $P$ values are calculated using $t$ tests

Published online January 2, 2019 
Table 2 Association of Dose Intensity and Rate of Developing Chronic Opioid Use, 2012 to 2014

\begin{tabular}{|c|c|c|}
\hline & $\begin{array}{l}\text { Coefficient } \\
\text { (percentage } \\
\text { point) }\end{array}$ & $\begin{array}{l}95 \% \\
\text { confidence } \\
\text { interval }\end{array}$ \\
\hline $\begin{array}{l}\text { Treated by high-dose prescrib- } \\
\text { ing surgeon versus low-dose } \\
\text { prescribing surgeon }\end{array}$ & 0.46 & $(0.04$ to 0.87$)$ \\
\hline Age & 0.002 & $(-0.05$ to 0.06$)$ \\
\hline Female & -0.17 & $(-0.64$ to 0.29$)$ \\
\hline White, non-Hispanic & 0.05 & $(-0.84$ to 0.94$)$ \\
\hline $\begin{array}{l}\text { Medicare-Medicaid dual } \\
\text { eligible }\end{array}$ & 1.47 & ( -0.83 to 3.77$)$ \\
\hline Currently disabled & 1.55 & $(-2.39$ to 5.49$)$ \\
\hline \multicolumn{3}{|c|}{ Conditions present in the prior year } \\
\hline Acute myocardial infarction & 2.30 & $(-2.26$ to 6.87$)$ \\
\hline Atrial fibrillation & 0.36 & $(-0.93$ to 1.65$)$ \\
\hline Chronic kidney disease & -0.45 & $\begin{array}{l}(-0.82 \text { to } \\
-0.08)\end{array}$ \\
\hline Congestive heart failure & -0.71 & $\begin{array}{l}(-1.33 \text { to } \\
-0.09)\end{array}$ \\
\hline Diabetes & 0.04 & $(-0.62$ to 0.70$)$ \\
\hline Hyperlipidemia & 0.03 & $(-0.50$ to 0.56$)$ \\
\hline Hypertension & -0.12 & $(-0.69$ to 0.45$)$ \\
\hline Alzheimer's disease & -1.07 & $(-2.47$ to 0.34$)$ \\
\hline Cerebrovascular disease & 0.49 & $(-0.82$ to 1.80$)$ \\
\hline $\begin{array}{l}\text { Chronic obstructive } \\
\text { pulmonary disease }\end{array}$ & -0.08 & $(-0.85$ to 0.69$)$ \\
\hline Depression & 0.35 & $(-0.34$ to 1.04$)$ \\
\hline
\end{tabular}

Author's calculation using data from Medicare from 2012 to 2014 Multivariable linear regressions were performed, controlling for the variables listed above (year is also controlled for, but the coefficients on year are not reported). The coefficient on "Treated by high-dose prescribing surgeon versus low-dose prescribing surgeon" therefore represents the adjusted percentage point difference in probability of developing chronic opioid use between those treated by high-dose prescribing surgeons and low-dose prescribing surgeons within the same practice. For comparison's sake, the average rate of chronic opioid use is $0.30 \%$ in our sample. Robust standard errors are used and are clustered at the practice level

I compared patients treated by high-dose and low-dose prescribing surgeons within the same practice. This strategy assumes patients do not select between surgeons in the same practice based on the surgeon's opioid-prescribing intensity, and therefore, patients treated within the same practice have similar propensities of developing chronic opioid use. The main explanatory variable was a binary indicator for whether the surgeon was a high-dose prescriber (in the top quartile of median dose in their practice) or low-dose prescriber (in the bottom quartile) [or highest and lowest median dose for practices with fewer than four surgeons], excluding practices where the difference between the upper and lower quartile was less than 50 morphine equivalents. The outcome was chronic opioid use, a binary indicator defined as 180 days or more of opioids supplied in the 365 days subsequent to the procedure, excluding the first 30 days. $^{3}$ I estimated linear probability models of the outcome as a function of dose intensity, controlling for patient age, sex, race and ethnicity, dual eligibility for Medicaid, current disability status, year, and diagnosis of the 11 chronic conditions listed in Table $1 .{ }^{3}$ I clustered standard errors at the practice level. I obtained study approval from the National Bureau of Economic Research.

\section{RESULTS}

The sample included 1360 patients treated by a low-dose prescriber and 1331 treated by a high-dose prescriber (Table 1). The rate of chronic opioid use after a meniscectomy was $0.30 \%$. The average median dose was 70 morphine equivalents for low-dose prescribers and 304 morphine equivalents for high-dose prescribers ( $p$ value $<0.001$ for the difference). There were no statistically significant differences in characteristics between patients treated by high-dose versus low-dose prescribers. After adjustment for patient characteristics and year, the difference in rate of chronic opioid use between those treated by high-dose versus low-dose prescribers was 0.46 percentage points (95\% CI 0.04 to 0.87 ) (Table 2). Results were largely unchanged when excluding those with any exposure to opioids (difference of 0.44 percentage points [95\% CI -0.03 to 0.91$]$ ). Results were unchanged when using logistic regression.

\section{DISCUSSION}

There is an over four-fold difference in median dose of first opioid prescription filled within the same practice in many orthopedic practices. Patients treated by high-dose prescribers within these practices had higher rates of developing chronic opioid use. Results are limited to the Medicare population with Part D undergoing meniscectomy and may not generalize to other populations. Differences within practices in surgery quality rather than differences in opioid prescribing may drive differences in the rate of developing chronic opioid use.

Acknowledgments: The author wishes to thank Samantha L. Burn for helpful comments on the paper.

Corresponding Author: Dan P. Ly, M.D., M.P.P.; Interfaculty Initiative in Health Policy, Harvard University, Cambridge, MA, USA (e-mail: danly@g.harvard.edu).

Funding This work was supported by the National Institute on Aging (Grant F32 AG060650-01).

\section{Compliance with Ethical Standards:}

Conflict of Interest: The author declares that he does not have a conflict of interest.

Disclaimer: No funding source played a role in the design and conduct of the study; collection, management, analysis, and interpretation of the data; preparation, review, or approval of the manuscript; and decision to submit the manuscript for publication. Dan P. Ly had full access to all the data in the study and takes responsibility for the integrity of the data and the accuracy of the data analysis.

Publisher's Note: Springer Nature remains neutral with regard to jurisdictional claims in published maps and institutional affiliations.

\section{REFERENCES}

1. Carey CM, Jena AB, Barnett ML. Patterns of potential opioid misuse and subsequent adverse outcomes in Medicare, 2008 to 2012. Ann Intern Med. 2018; 168:837-45. 
2. Department of Health and Human Services Behavioral Health Coordinating Committee. Addressing prescription drug abuse in the United States: current activities and future opportunities. 2014. Accessed at https:// www.cdc.gov/drugoverdose/pdf/hhs_prescription_drug_abuse_report_09. 2013.pdf on 12 October 2018 .
3. Barnett ML, Olenski AR, Jena AB. Opioid-prescribing patterns of emergency physicians and risk of long-term use. N Eng J Med. 2017;376:663-73.

4. Brat GA, Agniel D, Beam A, Yorkgitis B, Bicket M, Homer M, et al Postsurgical prescriptions for opioid naïve patients and association with overdose and misuse: retrospective cohort study. BMJ. 2018;360:j5790. 